\title{
Chapter 4 \\ The Role of the European Commission in the Development of the ETSI IPR \\ Policy and the Nature of FRAND \\ in Standardization
}

\author{
Eric L. Stasik
}

\section{Introduction}

There is a large body of research on fair, reasonable, and non-discriminatory (FRAND) focused on the licensing of Standard Essential Patents (SEPs) after a standard has been released to the public and implemented into products, but surprisingly little attention has been given to important role FRAND plays in the development of standards themselves. This chapter provides an overview of the European Commission's (EC) involvement in the development of the European Telecommunications Standard Institute's (ETSI) Intellectual Property Right (IPR) Policy which illuminates on the vital role that FRAND plays in the process of standards development.

FRAND is usually presented as a bi-lateral matter between SEP holders and licensees of SEPs which arises after standards have been implemented into products, but there is another absolutely fundamental aspect of FRAND which must not be over-looked and this is FRAND's practical and useful role in the rapid development and deployment of Information and Communications Technology (ICT) standards. For students of public policy, a review of the EC's role in the creation of ETSI and the EC's hands-on involvement in the development of ETSI's benchmark IPR Policy provides an example of successful — and limited-regulatory intervention and enables a deeper understanding of the problems associated with SEP licensing and the nature of the FRAND obligation.

E. L. Stasik (ه)

Avvika AB, Stockholm, Sweden

e-mail: eric.stasik@avvika.com

(C) The Author(s) 2018

A. Bharadwaj et al. (eds.), Multi-dimensional Approaches Towards New Technology,

https://doi.org/10.1007/978-981-13-1232-8_4 


\section{European Union's Initiative}

The EC is the European Union's (EU) executive branch. It is the only body in the EU that promotes the general interest of the EU and takes decisions on the EU's political and strategic direction. Green Papers are documents published by the EC to stimulate discussion on given topics at the European Level. The EC's Green Papers initiate a consultation process amongst relevant parties and may also give rise to legislative actions. ${ }^{1}$

Thirty years ago, Europe's telecommunications landscape was a patchwork of national state-owned monopolies which excluded competition, stifled innovation, and reeked of economic inefficiency. In 1987, the EC issued a Green Paper on the Development of the Common Market for Telecommunication Services and Equipment $(\operatorname{COM}(87) 290$ final) which proposed to liberalize and harmonize the telecommunications market within the EU. ${ }^{2}$ There were three components to the EC's telecommunications policy; the creation of common technical standards at the EU level; progressive liberalization of the equipment and services market across the EU; and the gradual privatization of state-owned telecommunication monopolies which would be handled at a national level. ${ }^{3}$ The ambitions of this policy were as much political as economic. As the EC's Green Paper observed, not only would 'a technically advanced, Europe-wide and low-cost telecommunications network' improve European competitiveness, it would achieve priority Community goals of fostering the Internal Market and strengthening Community cohesion. ${ }^{4}$ It was also simply a matter of timing. In its Green paper, the EC recognized that an 'inevitable trend' towards 'the convergence of telecommunications, computing, and applications of electronics in general' was already being manifested in 'the convergence of certain trends at nation levels' such as steps already taken 'to ensure the interoperability of networks, terminals, and services by actively promoting the standardization policy conducted at European level since 1984. ${ }^{, 5}$ In this light, the EC's actions could be seen as an effort to get in front of (or to simply catch up with) policy shifts that already had their own organic momentum. With regard to the nascent mobile communications industry, however, the EC took a commanding lead noting that 'five different incompatible systems' were implemented in member states and

\footnotetext{
${ }^{1}$ Glossary of Summaries: Green Paper (EUR-Lex) <http://eurlex.europa.eu/summary/glossary/ green_paper.html>.

${ }^{2}$ European Commission, Green Paper On The Development Of The Common Market For Telecommunications Services And Equipment (COM(87) 290) final.

${ }^{3}$ Micheal Blauberger, The Political Economy Of European Union Competition Policy: A Case Study Of The Telecommunications Industry-By T. Baskoy (2009) 47(4) Journal of Common Market Studies 919.

${ }^{4}$ European Commission (n 2) 12.

5 ibid 3.
} 
commenting critically that 'mobile systems have been one of the worst examples of lack of Community-wide compatibility'. ${ }^{6}$ To redress this hodgepodge of mobile networks, the EC called for the 'creation of a Community-wide market for terminals and equipment' noting that 'this concerns in particular the promotion of Europe-wide open standards, in order to give equal opportunity to all market participants'?

A sense of urgency was provided by the Community goal to complete the Single Market before 1 January $1993 .{ }^{8}$ The EC stressed that the time it takes for the establishment and common application of international standards must be substantially reduced, in order to maintain future network integrity and to promote the availability and interoperability of efficient Europe-wide and worldwide services. ${ }^{9}$ The EC proposed that the development of harmonized specifications for this liberalized market would be facilitated by the creation of a new European standardization body 'based on the current cooperation of the Telecommunications Administrations within Conference of Postal and Telecommunications Administration (CEPT) and CEN-CENELEC', ${ }^{10}$ but also having a fair representation of all relevant actors. ${ }^{11}$

\section{Setting up of ETSI}

In response to the EC's proposal, ETSI was set up in 1988 by the European CEPT, but outside of the CEN-CENELEC framework suggested by the EC. With the January 1993 deadline rapidly approaching, the EC issued another of its Green Papers (COM(90) 456 final) recommending that the process of technological integration had to be accelerated noting that ETSI 'represented a radical change in approach to European standardization insofar as it provided for the direct participation at European level of all interested parties in standardization work rather than for representation through national delegations headed by the national standards body'. ${ }^{12}$ National delegations headed by national standards bodies developed the CEN-CENELEC framework originally envisaged by the EC. By departing from the existing model ETSI offered the EC and European industry a choice: '... accept the present structure of standardization in Europe, from which European standards will emerge relatively slowly over the next few years, or it can decide to commit itself

\footnotetext{
6ibid, para 4.4.2, 88 .

$7_{\text {ibid, s II A, } 5 .}$.

${ }^{8}$ European Commission, 'Single Market Act - Frequently Asked Question' (2010) <http://europa.eu/ rapid/press-release_MEMO-10-528_en.htm>; The Single European Act which came into force in July 1987 set out a timeline for establishing the Single Market over a period up to the end of 1992. ${ }^{9}$ European Commission (n 2) 13.

$10_{\text {ibid } 22 .}$

${ }^{11}$ Rudi Bekkers and Isabelle Liotard, 'European Standards For Mobile Communications' (1999) 3 EIPR 110.

${ }^{12}$ European Commission, 'Green Paper on the Development of European Standardization: Action for Faster Technological Integration in Europe' COM (90) 456 final, paras 23, 16.
} 
whole-heartedly to the rapid development of common European standards'. ${ }^{13}$ As the EC pointed out 'Efficiency in the production of European standards is, from the EC's point-of-view, the highest priority; the operation of Community product legislation depends upon it'.

The departure from the CEN/CENELEC framework and the introduction of manufacturers and other interested parties into the standardization process significantly complicated matters with regard to intellectual property rights. As the EC noted in $\operatorname{COM}(90)$ 456:

The problem of industrial and [IPRs] as well as patents has become a serious issue within the context of standardization. Inclusion of such elements within a standard can lead to reinforcement of a dominant position within the market unless satisfactory conditions for use of such property have been agreed. In many cases, the lack of adequate procedures to resolve such problems has slowed down work and hampered the convergence toward harmonized solutions. ${ }^{14}$

The EC urged standards bodies 'to develop practical rules' and to find 'adequate solutions and practical means to resolve IPR and patent issues.' In particular, the EC explained:

Whenever a contribution to a European standardization body is covered by IPR or patents, sufficient information should be provided to allow the experts at the working group level to base their opinion as to whether to include specifications covered by IPR or patent rights on the actual situation, including, when appropriate, the applicable licensing conditions. Public inquiry should be envisaged only if fair and reasonable conditions have been achieved and duly noted. ${ }^{15}$

The EC summarized this by concluding: 'The inclusion of IPR and patents within standards should be subject to clear rules, which provide for the right of use of IPR and patents either free or on fair and reasonable terms.' ${ }^{, 16}$

The original ETSI Directives issued in March 1988 did not include an IPR Policy. ${ }^{17}$ On 16 December 1991, the EC published a follow-up (COM(91) 521 final) to the above-mentioned Green Paper on standards (COM(87) 290 final) in which it was stated (at paragraph $\mathrm{xi}$ ) that the EC would welcome the development by standards bodies 'of clear conditions for the inclusion of [IPRs] in standards.' The EC added that, '[i]n view of the importance and complexity of the issue for

\footnotetext{
${ }^{13}$ ibid, paras 32, 21.

${ }^{14}$ European Commission (n 12), paras 92, 46.

${ }^{15}$ ibid.

${ }^{16}$ ibid, para V, s B (ix), 53.

${ }^{17}$ 'A proposal for an IPR Policy by the group of incumbent operators known as the GSM Memorandum of Understanding (MoU) 'that suppliers must grant operators a free worldwide license for all patents they held to implement GSM, and indemnify operators for all claims of patent infringement by third parties' was quickly rejected.' See Rudi Bekkers and Joel West, 'IPR Standardization Policies And Strategic Patenting In UMTS' (25th Conference on Entrepreneurship and Innovation, Copenhagen, June 2008).
} 
[IPR], standardization, competition and trade policy, the EC intend[ed] to produce a separate communication on the subject. ${ }^{18}$

On 27 October 1992, the European Commission published its promised Communication on Intellectual Property Rights and Standardization (COM(92) 445 final). This Communication set forth 'a number of principles which [the EC] believes should form the basis of any internal rules which standards bodies may wish to elaborate. ${ }^{19}$

In $\operatorname{COM}(92) 445$ final, the EC explained that in the event that the rightholder (i.e., patent holder) agrees to make licenses for SEPs available, 'the terms for licenses must be fair, reasonable, and non-discriminatory.' The EC did not elaborate on what the terms 'fair and reasonable' might mean and indeed the EC warned: 'It is not feasible or appropriate to be more specific as to what constitutes 'fairness' or 'reasonableness' since these are subjective factors determined by the circumstances surrounding the negotiation. 20

The EC also opined that: The terms which the rightholder offers for use of his rights should be flexible enough to include the possibility, if the parties agree, of cross-licensing arrangements. ${ }^{21}$

\section{ETSI's IPR Policy}

ETSI's first attempt at an IPR Policy - the 1993 ETSI IPR Policy and Undertakingwas approved by the ETSI General Assembly held between 16th and 18th March 1993. From the beginning, the fundamental objective of ETSI's IPR Policy has been to enable the production and availability of telecommunication standards 'based on solutions which best meet the technical objectives of the European telecommunications sector .... 22 This is important. ETSI's mandate was not to achieve agreement on an existing set of standards - such as deciding on which existing national standards should prevail in the whole common market - ETSI's mandate was to produce new standards based on a set of commonly agreed technical objectives. This meant drawing from the best available existing technology and taking in new innovations, including technical solutions covered by patents and other IPR. ETSI standards and technical specifications were, from the beginning, expected to include solutions covered by patents and other IPRs (those of ETSI members and others).

\footnotetext{
${ }^{18}$ European Commission, 'Intellectual Property Rights and Standardization' COM (92) 445 final, Brussels, s 1.1.2.

${ }^{19}$ ibid, s 1.1.4.

${ }^{20} \mathrm{EC}$ (n 18), para 4.3.3.

${ }^{21}$ ibid, para 4.3.4.

${ }^{22}$ ETSI Directives, 'ETSI Intellectual Property Rights Policy' (ETSI, 1993) s 2.1.
} 
There is an important distinction to be made between a Standards Setting Organization (SSO) and a Standards Development Organization (SDO). SSOs are primarily concerned with achieving interoperability (such as selecting a standard railway gauge, defining a unit of weight or measure, or mandating the use of certain radio frequencies). In contrast, an SDO such as ETSI is concerned both with achieving interoperability as well as the development of new technologies and solutions in order to achieve certain performance objectives. Unresolved IPR issues in SDOs can present significant hindrances to the production of new standards.

The 1993 ETSI IPR Policy and Undertaking was crafted to reduce the risk to ETSI, Members, and others applying ETSI Standards, that 'investment in the preparation, adoption and applications of STANDARDS could be wasted as a result of an Essential IPR for a standard being unavailable'. ${ }^{23}$ Patents incorporated into standards which are not available for license under any terms, or which were not available for license under FRAND terms and conditions would effectively block use of the standard frustrating the entire goal of standardization.

The 1993 ETSI IPR Policy also included an Undertaking which, beyond requiring that licenses granted 'be non-exclusive, on fair, reasonable, and non-discriminatory terms and conditions', imposed a list of items to be included in the scope of license and the disclosure of licensing terms, including 'the maximum royalty rate it will demand for the grant of licenses.... ${ }^{24}$

The attempt to define FRAND more specifically within the context of standardization was met with almost immediate opposition.

These and other arrangements gave rise to a complaint lodged on 22 June 1993 by the Computer and Business Equipment Manufacturers Association (CBEMA), most of whose members are also members of ETSI, alleging infringement of both Articles 85 and 86 resulting from ... the obligation to sign the undertaking which in CBEMA's view amounted to a compulsory licensing scheme. ${ }^{25}$

The issues raised by the 1993 ETSI IPR Policy and Undertaking were never decided on formally by the EC, in view of the fact that the undertaking and any reference thereto in the policy were abandoned by ETSI's General Assembly of 22 and 23 November 1994 in order to achieve greater consensus amongst ETSI members, and the complaint subsequently withdrawn. ${ }^{26}$

\footnotetext{
${ }^{23} \mathrm{EC}$ (n 18), ss 2.1.12, 4. 'These economic objectives can, of course, only be realized insofar as standards are made known and available to the widest possible number of interested parties on fair and reasonable terms. Consequently, a standard is by definition a publicly-available document and the technical specification which is not available to all potential users is not a standard.'

${ }^{24}$ ETSI (n 22) Version 005.

${ }^{25}$ Articles 85 and 86 are the two fundamental provisions of European competition law as defined by the Treaty of Rome in 1957. These were renumbered as Articles 81 and 82 by the Treaty of Amsterdam in 1997, and renumbered once again to the present Articles 101 and 102 by the Treaty of the Functioning of the European Union (TFEU) ratified in 2007. Article 101 (formerly 85 and then 81) prohibits cartels and anticompetitive agreements; Article 102 (formerly 86 and then 82) prohibits the abuse of a dominant position.

${ }^{26}$ Official Journal of the European Communities No. C 76/5, Notice pursuant to Article 19(3) of Council Regulation No. 17 concerning case No. IV/35.006 - ETSI interim IPR policy, 28 March 1995.
} 
ETSI itself found a solution before the EC could take action and the solution was to use, verbatim, the licensing conditions proposed by the EC in $\operatorname{COM}(92) 445$ final.

The ETSI Interim IPR Policy approved by the ETSI General Assembly at its specially convened meeting held on 23 November 1994, in Nice, France abandoned the Undertaking and replaced it with Section 6.1 on the availability of licenses:

'6.1 When an ESSENTIAL IPR relating to a particular STANDARD is brought to the attention of ETSI, the Director of ETSI shall immediately request the owner to give within three months an undertaking in writing that it is prepared to grant irrevocable licences on fair, reasonable, and non-discriminatory terms and conditions under such IPR to at least the following extent:

MANUFACTURE, including the right to make or have made customised components and sub-systems to the licensee's own design for use in MANUFACTURE;

sell, lease, or otherwise dispose of EQUIPMENT so MANUFACTURED;

repair, use, or operate EQUIPMENT; and

use METHODS.

The above undertaking may be made subject to the condition that those who seek licences agree to reciprocate.'

The language of Section 6.1 has proven to be durable. In the most current version of the ETSI IPR Policy (5 April 2017) is reproduced below with changes from the 1994 version in italics.

6.1 When an ESSENTIAL IPR relating to a particular STANDARD or TECHNICAL SPECIFICATION is brought to the attention of ETSI, the Director-General of ETSI shall immediately request the owner to give within three months an irrevocable undertaking in writing that it is prepared to grant irrevocable licences on fair, reasonable, and non-discriminatory (FRAND) terms and conditions under such IPR to at least the following extent:

MANUFACTURE, including the right to make or have made customized components and sub-systems to the licensee's own design for use in MANUFACTURE;

sell, lease, or otherwise dispose of EQUIPMENT so MANUFACTURED;

repair, use, or operate EQUIPMENT; and

use METHODS.

The above undertaking may be made subject to the condition that those who seek licences agree to reciprocate.

Since the 1993 Undertaking was abandoned, and the availability of licenses under FRAND governed by Section 6.1, ETSI has resisted all attempts to further define 'fair, reasonable, and non-discriminatory' beyond the plain, literal meaning of those words as they were handed down from the EC and placed into the ETSI IPR Policy. ${ }^{27}$ The ETSI Guide on IPRs explains that 'commercial terms are a

\footnotetext{
${ }^{27}$ Roger Brooks and Damien Geradin, 'Interpreting And Enforcing The Voluntary FRAND Commitment' (20 July 2010) International Journal of IT Standards and Standardization Research.
} 
matter for discussion between the IPR holder and the potential licensee, outside of ETSI.' members are reminded that 'Specific licensing terms and negotiations are commercial issues between the companies and shall not be addressed within ETSI. ${ }^{28}$ The ETSI Guide on IPRs also reminds the chairs of technical bodies that 'the Chairman shall not allow any discussion on commercial issues in the Technical Bodies, in particular but not limited to discussions on details of specific licensing terms and conditions. ${ }^{29}$ ETSI's Guidelines for Antitrust Compliance reminds participants in ETSI Technical Committees and Working Groups to (please) not 'Discuss any disclosure of licensing price or terms, product or service price or terms, pricing methods, profits, profit margins, cost data, production plans, market share or territories in the course of any ETSI activity. ${ }^{30}$ The Horizontal Guidelines state "where participation in standard-setting is unrestricted and the procedure for adopting the standard is transparent, standardization agreements which ... provide access to the standard on fair, reasonable, and non-discriminatory terms will normally not restrict competition within the meaning of Article 101(1). ${ }^{31}$ It has to be remembered that ETSI consists largely of groups of competitors and ETSI's own work is subject to the rules of competition law. ${ }^{32}$ Moreover, in addition to having to comply with anti-competition guidelines, as a wholly practical matter ETSI's technical working groups are ill-equipped to handle commercial licensing issues.

The EC's view expressed in $\operatorname{COM}(92) 445$ final that 'It is not feasible or appropriate to be more specific as to what constitutes 'fairness' or 'reasonableness' since these are subjective factors determined by the circumstances surrounding the negotiation' proved to be prophetic, practicable, and durable. The explanation is simple: FRAND promotes the work of standards bodies. FRAND may be an incomplete solution for the licensing of SEPs (as intended), but it is a complete solution to the problem of rapidly producing standards which incorporate SEPs and this is what many SEP users seem to take for granted. ETSI does not determine what FRAND is because this is expressly not the job of ETSI. ETSI's job is to rapidly produce technically advanced standards which are available for public use.

When developing something as complex, large, ambitious and cutting-edge as a complete mobile telecommunications system, contentious commercial IPR licensing issues are unavoidable. The potential for commercial conflict arising from the protection of IPR implemented in products and services that comply with ETSI

\footnotetext{
${ }^{28}$ 'ETSI Guidelines On IPRs’ (ETSI, 2013) s 4.1.

${ }^{29}$ ibid, s 2.3 .

${ }^{30}$ 'ETSI Guidelines For Antitrust Compliance' (ETSI, 2011); 'ETSI Directives Version 36' (ETSI, 2016) <https://portal.etsi.org/directives/36_directives_jun_2016.pdf>.

${ }^{31}$ 'Guidelines On The Applicability Of Article 101 Of The Treaty Of The Functioning Of The European Union To Horizontal Co-Operation Agreements' (2011) C11/1-72, s 280.

${ }^{32}$ 'Regulation (EU) No. 1025/2012 of the European Parliament and Council of 25 October 2002' (2012) L 316/12-33; 'The European standardization organizations are subject to competition law to the extent that they can be considered to be an undertaking or an association of undertakings within the meaning of Articles 101 and 102 TFEU.'
} 
standards is compounded by ETSI's large and heterogeneous membership, ${ }^{33}$ but thanks to FRAND, the ETSI IPR Policy, and the resulting hands-off treatment of SEP licensing matters by ETSI as described above, SEP licensing issues do not themselves present any hinderance to the work of standards development. It is not difficult to imagine the chaos which would be introduced in the standardization process if the 'smartphone patent wars' were to be fought out during the process of standardization. In this regard, FRAND is a constructive ambiguity ${ }^{34}$ which enables new standards to be peacefully developed and released on a rapid and regular basis leaving it to implementers, both licensors and licensees, of the standard to solve any commercial licensing issues once the standard is available for use. This is a feature of FRAND, not a flaw and this practical side of FRAND is the absolute keystone of the arch when it comes to producing high-quality standards in quick succession and getting goods and services available to consumers.

The success of the EC's creation of ETSI, its role in the development of ETSI's IPR Policy, and its limited intervention in defining FRAND is plainly evident. At the end of 1992, there were six million mobile subscribers in Europe. ${ }^{35}$ In 2015, the GSMA reported $430 \mathrm{~m}$ unique mobile subscriptions across Europe and a total of $684 \mathrm{~m}$ connections (excluding M2M). The GSMA estimates that the whole ecosystem of the mobile communications industry contributed $€ 500$ bn to Europe's GDP in 2014 (3.2\% of GDP), generated operator revenues in 2015 of $€ 150$ bn, provided $2.3 \mathrm{~m}$ direct jobs, and an additional $1.5 \mathrm{~m}$ indirect jobs. In terms of consumer benefit, the GSMA reported: 'Based on unique subscribers, Europe is the most penetrated region globally, with a near-saturation level of $78 \%$, nearly 10 percentage points above both North America and CIS. ${ }^{36}$ At present, worldwide, there are nearly five billion unique mobile subscribers and over eight billion mobile connections (including M2M), producing annual revenues of $\$ 1.06 \mathrm{~T}^{37}$ The World

\footnotetext{
${ }^{33}$ 'Current Members' (ETSI) <http://www.etsi.org/membership/current-members>; ETSI today has over 800 members from 68 countries across five continents. 'Amongst our present members are the biggest players in ICT and there are many government and regulatory bodies. But ETSI is the home of small companies, universities and research bodies too. Size is unimportant because our members work together as partners in the standardization process.'

${ }^{34}$ Drazen Pehar, 'Use of Ambiguities in Peace Agreements' in J. Kurbalija and H. Slavik (eds), Language and Diplomacy (Malta 2001). 'Constructive ambiguity' is a term coined in the 1970s by former US Secretary of State Henry Kissinger to describe the negotiating tactic where ambiguous language is inserted into agreements in order to overcome an impasse so that further negotiations can take place.

35، Annual Economic Report' (European Telecommunications Network Operaror's Association, 2012); N.B. ETNO's membership of 38 operators in 35 countries is larger than the expanded Union and includes Turkey, Switzerland, and Norway.

${ }^{36}$ 'The Mobile Economy Europe' (GSMA, 2015) <https://www.gsma.com/mobileeconomy/ archive/GSMAMEEurope_2015.pdf>.

${ }^{37}$ 'Definitive data and analysis for the mobile industry' (GSMA Intelligence, 2018) https://www. gsmaintelligence.com accessed 10 May 2017.
} 
Bank estimates that $96 \%$ of the world's population is covered by mobile radio services and globally there are 93 mobile cellular subscriptions per 100 people. $^{38}$

\section{Conclusion}

The introduction of new generations of mobile standards has been rapid and relentless - and led from Europe. The world's first GSM (2G) call was made on 1 July 1991 in a European capital (Helsinki) using equipment supplied by Nokia. In 2001, the world's first voice call over WCDMA (3G) was made in the UK by Ericsson and Vodafone. ${ }^{39}$ The world's first commercial LTE (4G) network was turned on in another European capital (Stockholm) in 2009 using equipment supplied by Ericsson. ${ }^{40}$ As 3 GPP noted about LTE (4G): 'Never before has a new radio technology made it to the market so quickly and widely after the finalization of the first version of the standards. ${ }^{41}$ In July 2016, the major European operators published a $5 \mathrm{G}$ manifesto which indicated a target of launching $5 \mathrm{G}$ in at least one city in each of the European member states by $2020 .^{42}$ Telecom Italia announced that the world's first nationwide $5 \mathrm{G}$ network will be installed in the micro-state of San Marino during $2018 .^{43}$ It is predicted that $5 \mathrm{G}$ networks will cover a third of the world's population by 2025 . $^{44}$

The primary goal of ETSI's IPR Policy has been the rapid creation and availability of new technical standards such as $2 \mathrm{G}, 3 \mathrm{G}, 4 \mathrm{G}$, and $5 \mathrm{G}$. In this regard, the ETSI IPR Policy - and in particular the FRAND licensing commitment - is a proven, durable and successful result of a sagacious public policy.

\footnotetext{
${ }^{38}$ 'World Development Indicators: Power And Communications' (The World Bank) <http://wdi. worldbank.org/table/5.11>; Of course, statistics on the number of subscriptions per capita do not account for people who have multiple phones, or a phone plus a tablet, eReader, or PC with a cellular connection.

39، Årsredovisning' (Ericsson, 2001): 'After having started production of commercial radio base stations in March, we completed the world's first successful call in the field using 3GPP release 99 in April in Vodafone's network'.

${ }^{40}$ 'World's First 4GLTE Network Goes Live Today in Stolkhom' (Ericsson, 2009) <https://www. ericsson.com/en/press-releases/2009/12/1360881-worlds-first-4glte-network-goes-live-today-instockholm>.

${ }^{41}$ Kevin Flynn, '3GPP System Standards Heading Into The 5G Era' $(3 G P P, 2018)<$ http://www. 3gpp.org/news-events/3gpp-news/1614-sa_5g>.

${ }^{42 ،}$ 'The Mobile Economy' (GSMA, 2017).

${ }^{43}$ Nic Fildes, 'San Marino Set To Become First Country Upgraded To 5G Nationwide' Financial Times (17 July 2017) <http://mvnoblog.com/san-marino-set-to-become-first-country-upgraded-to5g-nationwide-financial-times/>.

${ }^{44}$ ibid.
} 
Open Access This chapter is licensed under the terms of the Creative Commons Attribution 4.0 International License (http://creativecommons.org/licenses/by/4.0/), which permits use, sharing, adaptation, distribution and reproduction in any medium or format, as long as you give appropriate credit to the original author(s) and the source, provide a link to the Creative Commons license and indicate if changes were made.

The images or other third party material in this book are included in the book's Creative Commons license, unless indicated otherwise in a credit line to the material. If material is not included in the book's Creative Commons license and your intended use is not permitted by statutory regulation or exceeds the permitted use, you will need to obtain permission directly from the copyright holder.

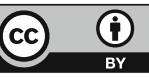

